\title{
Analysis of the costs and quality of cardiovascular care in oncological monitoring
}

\author{
Élide Sbardellotto Mariano da Costa ${ }^{1 *}$, Adriano Hyeda²
}

${ }^{1}$ Auditing Physician, Specialist Degree in Cardiology from Pontifícia Universidade Católica do Paraná (PUC-PR). Executive Master of Business Administration (MBA) in Health Management from Instituto Superior de Administração e Economia, Fundação Getulio Vargas (ISAE/FGV). Graduate Degree in Health Auditing, Feluma/Fundação Unimed, Curitiba, PR, Brazil

${ }^{2}$ Specialist Degree in Medical Oncology from Universidade Federal do Paraná (UFPR). Occupational Physician Degree from PUC-PR. Executive MBA in Health Management from ISAE/FGV, Curitiba, PR, Brazil

Study conducted within the scope of a self-governing health insurance provider in the State of Paraná, Brazil

*Correspondence Address: Rua José Loureiro, 195, $12^{\circ}$ andar, Centro Curitiba, PR - Brazil Postal code: 80010-000 elide@onda.com.br

Academic affiliation: This article is part of the lead author's final project in the Graduate course of Health Auditing at Feluma/Fundação Unimed

\section{SUMMARY}

Objective: To analyze the health care costs specifically related to cardiovascular diseases, which were spent by patients of a private healthcare provider in southern Brazil, after their diagnosis of cancer.

Method: We developed an observational, cross-sectional, retrospective study, with a qualitative-quantitative strategy, through the activity of analytical internal audit of medical accounts.

Results: 860 accounts from 2012 to 2015 were analyzed, 73\% referred to female users, with average age of 62.38 years, and a total direct cost of BRL 241,103.72. There was prevalence of $37 \%$ of breast cancer, $15 \%$ of prostate cancer and $9 \%$ of colon cancer. In relation to the cardiovascular care, $44 \%$ were consultations, $44 \%$ were complementary exams, $10 \%$ were emergency care, and $3 \%$ were hospitalizations. Regarding the health care costs with cardiovascular services, higher costs were in hospitalizations (51\%), followed by complementary exams (37\%), consultations (8\%) and emergency care (4\%).

Conclusion: The cancer survivors commonly use health care in other specialties such as cardiology, and the main cost refers to hospitalization. It is recommended to invest in prevention (consultation and complementary exam) as well as in programs of chronic disease management to reduce costs and improve the quality of health care.

Keywords: supplemental health, costs and cost analysis, cardiology services, oncology, disease prevention.

\section{INTRODUCTION}

With improvement in the prevention and treatment of infectious diseases, as well as the sanitary and socioeconomic conditions of the population, there has been an increase in life expectancy and, as a result, cardiovascular diseases and cancer have become leading causes of death. ${ }^{1-4}$ Cancer is among the leading causes of morbidity and mortality worldwide, with approximately 14 million new cases and 8.2 million of deaths related to the disease in 2012. There will be an estimated increase of $70 \%$ in new cases of cancer over the next two decades, and the greatest effect will be focused on low and middle-income countries. ${ }^{5}$ In Brazil, the estimate for the year 2014/2015 indicates the occurrence of 576,000 new cases of cancer. ${ }^{2}$

In addition to the increased number of new cases of cancer, progress in the treatment and early diagnosis of the disease has resulted in a considerable increase in the survival of such patients. In the United States, there was a $20 \%$ reduction in mortality caused by cancer between 1991 and $2010 .{ }^{6}$ The increased survival rate in cancer patients has pushed this population to suffer morbidity and mortality caused by other conditions, such as cardiovascular disease.

A patient diagnosed with cancer who undergoes treatment (chemotherapy, radiotherapy or surgery) acquires a potential risk towards the deterioration of their cardiovascular health. ${ }^{1,3,4,7-10}$ There is an association between cardiovascular risk factors specific to the individual plus the aggravating factor acquired from the cancer's pathophysiology and the side effects of oncological treatments. In this context, cardiotoxicity is defined as the effects of external agents (chemical or physical) that negatively 
interfere with the heart, causing structural, electrical, and functional changes to the myocardium. ${ }^{11}$

Cancer survivors with some evidence of cardiotoxicity present a mortality rate that is on average eight times higher than that of the general population. The main symptoms include: heart failure (15 times higher); myocardial ischemia (ten times higher); central thromboembolic events such as cerebrovascular accident (nine times higher) and peripheral events such as deep venous thrombosis and pulmonary thromboembolism (4 to 6 times higher). It has been noted that the main events occur due to the association of risks for atherosclerotic disease with higher incidence of thrombogenicity, coagulopathy and thrombocytopenia. ${ }^{7,12-17}$ Other manifestations of cardiotoxicity related to cancer treatment include valve changes, arrhythmias (atrial fibrillation and prolonged QTc being the most frequent), hypertension, and pericarditis. ${ }^{7,18,19}$ Cardiotoxicity related to cancer treatment may become manifest at any time, with reports of it occurring within 45 years or more after the end of treatment. . $^{11,20,21}$

Theoretically, any chemotherapy has the potential to cause toxicity. ${ }^{7}$ The main chemotherapeutic agents that present cardiotoxicity include anthracyclines (such as doxorubicin, epirubicin, and idarubicin), alkylating agents (cyclophosphamide and ifosfamide), antimicrotubule agents (such as paclitaxel and docetaxel), monoclonal antibodies (such as trastuzumab, bevacizumab), and tyrosine kinase inhibitor (such as sunitinib). ${ }^{7}$ So, in theory, every patient undergoing cancer treatment may develop some degree of cardiovascular damage, regardless of the chosen treatment, which could be compounded by their individual cardiovascular risk factors.

The Brazilian Societies of Cardiology and Oncology have established a Guideline for maintaining periodic monitoring of cardiotoxicity during infusion cycles as an essential strategy for preventing severe and irreversible myocardial damage. As such, continued monitoring of clinical manifestations (such as the assessment of nonspecific symptoms like tiredness, fatigue, and functional limitation for everyday activities) is necessary. ${ }^{7,22,23}$ It is recommendable to take the medical history, perform a physical examination and additional cardiovascular examinations (12-lead electrocardiogram at rest and baseline assessment of left ventricular function using echocardiography, scintigraphy or radionuclide ventriculography via cardiac catheterization) at the beginning of treatment and then every 3,6 or 12 months, depending on the chemotherapy used and the individual cardiovascular risk factors of the cancer patients. ${ }^{7,24}$
The main objective of our research was to analyze the cost of care for cardiovascular diseases in users of a health insurance provider after the diagnosis of any type of cancer, through the analytical internal audit of the medical/ hospital accounts. The secondary objective was to compare our results with data from the scientific literature and to establish hypotheses justifying the use of cardiovascular care in cancer survivors.

\section{Method}

A retrospective, cross-sectional, observational study with a qualitative and quantitative strategy was conducted using the data obtained through the internal audit system of a self-governing health insurance provider (OPS) located in southern Brazil, in the period covering January 2012 to March 2015 (38 full months). This health insurance provider is a part of the Brazilian supplementary health sector in accordance with the current regulations issued by the National Supplementary Health Agency (ANS). ${ }^{25}$

Two copies of the agreement for the use of data for research (TCUD) were signed by the research team and the health insurance provider whose data was analyzed in this study, as provided for international research documents and the National Health Council resolution 466/12.

In our study, there was only access to epidemiological data such as gender, age group, and the International Classification of Diseases and Related Health Problems (also known as ICD-10), as well as to health care costs. ${ }^{26}$ Our data was collected from computerized reports that are part of the internal audit services and billing of accounts at the health insurance provider. Any data that could identify patients was excluded from the research.

Sample size was defined as the number of accounts initially recorded in the internal audit system as patients with diseases classified under chapter II of the ICD-10 (Neoplasms [tumors] - C00 to D48) who subsequently presented used health care services related to circulatory system diseases (CSD) (classified in chapter IX - I00 to I99). ${ }^{26}$ The estimated sampling error value in this study was $E \leq 0.05$ and the total population of users of the health insurance provider analyzed was 77,666 users, with a sample size of 860 accounts. This value was considered representative of the total population, referring to a confidence interval of $96 \%$ (calculated using the formula $n=\left[N \times n^{\circ}\right] /\left[N+n^{\circ}\right]$ and $n^{\circ}=1 /(E)^{2}$, where $N$ is the variable eligible for auditing, $\mathrm{E}$ is the tolerable sampling error, $\mathrm{n}^{\circ}$ is the first approximation of the sample size that should be analyzed, and $\mathrm{n}$ is the final size of the sample to be analyzed). 
This analysis excluded the accounts that did not meet both inclusion criteria, that is, being initially registered under ICD-10 code of oncological origin (C00 to D48) and subsequent use of healthcare services related to CID 10 "I". Skin neoplasms were also excluded from the sample because treatment for such is usually surgical and curative, and do not interfere with the patient's cardiovascular risks.

To analyze the economic impact of the use of cardiovascular care services by cancer survivors, the total direct costs were compared in the 860 accounts selected. The following absolute costs were accounted for:

- Elective medical consultations.

- Emergency consultations at the chest pain unit (UDT).

- Hospitalizations (with clinical, hemodynamic and/ or surgical care).

- Supplementary examinations, for example, electrocardiogram, chest X-ray, exercise stress test, cardiopulmonary exercise test, transthoracic echocardiography, echocardiography under physical or pharmacological stress, transesophageal echocardiography, Doppler ultrasound of vessels, ambulatory blood pressure monitoring (ABPM), portable monitoring of cardiac electrical activity (HOLTER), myocardial scintigraphy at rest and under physical or pharmacological stress, chest tomography, angiography of vessels, electrophysiological study, and pulmonary artery catheterization (PAC).

Each account represented the direct costs of a patient in a specific health care modality (elective consultation, emergency care, supplementary examinations or admissions). The costs were recorded in national currency (the Brazilian Real - BRL) at the time of the study, according to the values established by the health insurance provider, which are in accordance with the ANS legislation. ${ }^{25}$ The absolute data (non-itemized direct total costs) were made available through the accounting reports provided by the internal audit program and analysis of medical/hospital accounts. Indirect costs will be analyzed in a subsequent study.

Qualitative data (gender, age, and ICD-10) were described using frequencies and percentages. Quantitative data from the costs were described using maximums, minimums, arithmetic means, standard deviations (SD) and $95 \%$ confidence intervals $(95 \mathrm{CI})$ with significance at $\mathrm{p}<0.05$. The data was tabulated and analyzed using spreadsheets and graphs (formatted Excel ${ }^{\circledR}$ in the Office 2007 ${ }^{\circledR}$ system for Windows ${ }^{\circledast}$ ).

\section{Results}

We analyzed 860 accounts in the period from 2012 to 2015 (38 months), with a monthly average of $71.66 \mathrm{ac}-$ counts, ranging from 45 to 108 per month, with a median of $68, \mathrm{SD} \pm 95 \%$ and $95 \mathrm{CI} 70.161-73.159$. Seventy-three percent (73\%) of the accounts (628) belonged to female users and $27 \%$ belonged to male users (232). The average age was 62.38 years, ranging from 25 to 89 years (87\% of the population analyzed was aged over 50 years), with $\mathrm{SD} \pm 9.91$ and $95 \mathrm{CI}$ 61.71-63.04.

The distribution of the conditions classified by the ICD-10 can be seen in Chart 1, showing a predominance of breast neoplasms (37\%) followed by prostate (15\%) and colon $(9 \%)$ cancers. The mean age observed in the three main types of cancer was 62.10 years among the breast neoplasms (ranging from 40 and 89 , median of 61 , $\mathrm{SD} \pm 9.09,95 \mathrm{CI} 60.08-61.91), 70.49$ years among the prostate neoplasms (ranging from 52 to 86, median of 72, $\mathrm{SD} \pm 8.26,95 \mathrm{CI} 70.50-73.49)$, and 66.16 years among the colon neoplasms (ranging from 48 to 78 years, median of $68, \mathrm{SD} \pm 6.13$, 95CI 65.16-0.83).

The cardiovascular care were consultations, representing $44 \%$ (375), supplementary examinations requested in elective or emergency consultations, representing 44\% (375), emergency services at the UDT, representing 10\% (84), and clinical, surgical or hemodynamic hospitalizations, representing $2 \%$ (26). The direct total cost of cardiovascular care services in this population was BRL 241,103.72, with a monthly average of BRL 270.36, ranging from BRL 12.48 to BRL $23,883.89$. This total cost was distributed as follows: $8 \%$ on consultations (BRL 20,034.48), $4 \%$ on emergency visits at the UDT (BRL 8,574.12), 37\% on supplementary tests (BRL 89,931.18) and 51\% on hospitalizations (BRL $122,563.94)$. The distribution of the direct costs in relation to the ICD-10 code of each account is shown in Table 1.

Specifically analyzing the two groups presenting higher costs (supplementary examinations and hospitalizations), we can see that ten different types of examination were requested: $42 \%$ ultrasound (including transthoracic echocardiography, echocardiography under physical or pharmacological stress, transesophageal echocardiography, and Doppler ultrasound of vessels), $18 \%$ exercise stress test, $14 \%$ electrocardiogram, $8 \%$ scintigraphy, $7 \%$ ABPM, $4 \%$ radiography, $3 \%$ HOLTER, $2 \%$ tomography and angiography, $1 \%$ cardiopulmonary exercise test, and less than $1 \%$ for CAT. Note that $74 \%$ of the requested examinations corresponded to three categories: ultrasound, stress testing, and electrocardiography. Eighty-four percent (84\%) of the requests included only one supplementary examination, $12 \%$ in- 
cluded two, and $4 \%$ included three or more examinations. In relation to hospitalization, $15 \%$ of the hospitalizations presented a need for surgical intervention, 35\% were clinical admissions and 50\% required hemodynamic intervention ( $\mathrm{SD} \pm 4.50$ hospitalizations and $95 \mathrm{CI} 6.92-10.39$ ). Home care services were not used in this sample.

Cardiovascular care accounts related to breast neoplasms accounted for $44 \%$ (138) of supplementary tests, $40 \%$ (127) of elective consultations, $12 \%$ (38) of emergency care at the UDT, and 4\% (13) of admissions. The greatest costs involved hospitalizations ( $52 \%$ or BRL 50,924.55) and supplementary examinations ( $35 \%$ or BRL $34,212.15$ ). With respect to the cardiovascular care accounts associated with prostate neoplasms, $42 \%$ (56) were related to supplementary examinations, $42 \%$ (55) to elective consultations, $11 \%$ (15) to emergency care at the UDT, and 5\% (6) to admissions. The greatest costs of these accounts were those of hospitalizations $(65 \%$ or BRL $37,499.39)$ and supplementary examinations (27\% or BRL $15,641.51)$. Finally, the cardiovascular care accounts related to colon neoplasms accounted for $53 \%$ (39) of the supplementary examinations, 38\% (28) were elective consultations, $5 \%$ (4) hospitalizations, and 4\% (3) emergency care at the UDT. The greatest costs of these accounts were those of hospitalizations (69\% or BRL 17,121.71) and supplementary examinations $(23 \%$ or BRL $5,848.45)$.

\section{Discussion}

The development of new health technologies, innovations in treatment and early diagnosis have contributed to increasing the survival rate of cancer patients. At the same time, many cancer survivors ended up being affected by other chronic diseases, including those of cardiovascular origin. Studies have demonstrated the existence of a correlation between the risk factors for cancer and cardio-neural-vascular diseases, mainly regarding lifestyle, such as smoking, physical inactivity, obesity and diet, and more. Furthermore, it is known that chemotherapy and radiotherapy contribute to the development and/or acceleration of the pathophysiology of cardiovascular disease. ${ }^{7-10,27}$ Therefore, cardiovascular events in cancer survivors are related not only to the specific cardiotoxicity of the cancer treatment but also the risk factors attributed to longevity, lifestyle and nutrition, which are intensified by the pathophysiology of the cancer itself.

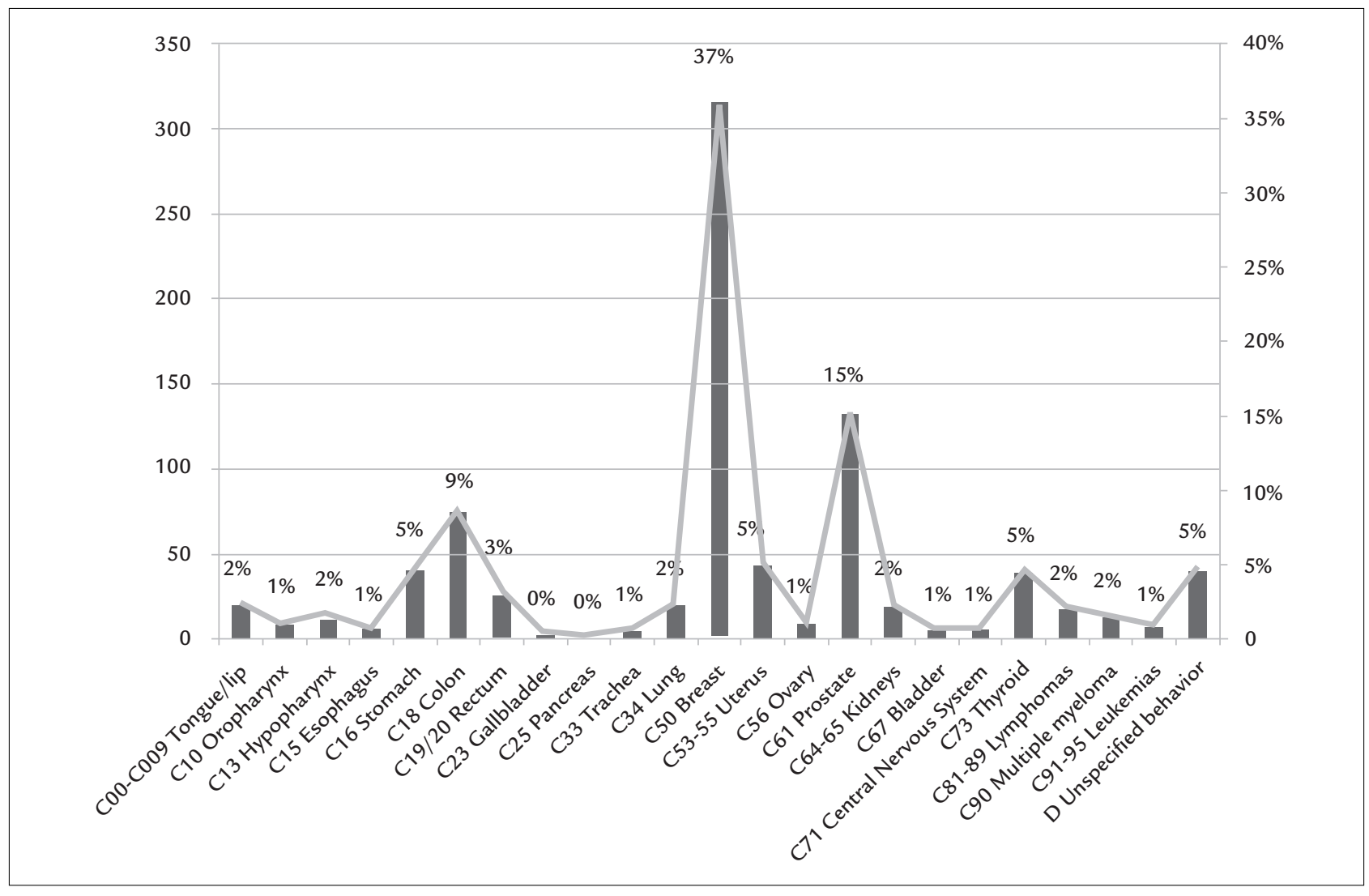

CHART 1 Distribution of diseases in the accounts analyzed according to the ICD-10 classification. 
TABLE 1 Distribution of diseases according to the ICD-10 classification and respective costs of cardiovascular care.

\begin{tabular}{|c|c|c|c|c|c|}
\hline Characteristics & $\begin{array}{l}\text { Number of } \\
\text { accounts }(n=860)\end{array}$ & Percentage & Total cost of accounts & Percentage & $\begin{array}{l}\text { Average cost } \\
\text { per account }\end{array}$ \\
\hline C00-C009 Tongue/lip & 20 & $2 \%$ & BRL $3,760.48$ & $2 \%$ & BRL 188.02 \\
\hline C10 Oropharynx & 8 & $1 \%$ & BRL 2,935.94 & $1 \%$ & BRL 366.99 \\
\hline C13 Hypopharynx & 13 & $2 \%$ & BRL 3,550.53 & $1 \%$ & BRL 273.12 \\
\hline C15 Esophagus & 5 & $1 \%$ & BRL 314.50 & $0 \%$ & BRL 62.90 \\
\hline C16 Stomach & 41 & $5 \%$ & BRL 4,983.19 & $2 \%$ & BRL 121.54 \\
\hline C18 Colon & 74 & $9 \%$ & BRL 24,930.40 & $10 \%$ & BRL 336.90 \\
\hline C19/20 Rectum & 25 & $3 \%$ & BRL 3,466.46 & $1 \%$ & BRL 138.66 \\
\hline C23 Gallbladder & 2 & $0 \%$ & BRL 132.00 & $0 \%$ & BRL 66.00 \\
\hline C25 Pancreas & 1 & $0 \%$ & BRL 70.48 & $0 \%$ & BRL 70.48 \\
\hline C33 Trachea & 5 & $1 \%$ & BRL 2,036.83 & $1 \%$ & BRL 407.37 \\
\hline C34 Lung & 20 & $2 \%$ & BRL 4,564.00 & $2 \%$ & BRL 228.20 \\
\hline C50 Breast & 316 & $37 \%$ & BRL 97,460.93 & $40 \%$ & BRL 308.42 \\
\hline C53-55 Uterus & 43 & $5 \%$ & BRL 3,668.45 & $2 \%$ & BRL 85.31 \\
\hline C56 Ovaries & 9 & $1 \%$ & BRL 1,032.73 & $0 \%$ & BRL 114.75 \\
\hline C61 Prostate & 132 & $15 \%$ & BRL 57,475.27 & $24 \%$ & BRL 435.42 \\
\hline C64-65 Kidneys & 19 & $2 \%$ & BRL 3,779.57 & $2 \%$ & BRL 198.92 \\
\hline C67 Bladder & 5 & $1 \%$ & BRL 256.00 & $0 \%$ & BRL 51.20 \\
\hline C71 Central Nervous System & 6 & $1 \%$ & BRL 173.68 & $0 \%$ & BRL 28.95 \\
\hline C73 Thyroid & 39 & $5 \%$ & BRL $8,186.57$ & $3 \%$ & BRL 209.91 \\
\hline C81-89 Lymphomas & 17 & $2 \%$ & BRL 3,636.76 & $2 \%$ & BRL 213.93 \\
\hline C90 Multiple myeloma & 13 & $2 \%$ & BRL 4,278.09 & $2 \%$ & BRL 329.08 \\
\hline C91-95 Leukemias & 7 & $1 \%$ & BRL $4,360.60$ & $2 \%$ & BRL 622.94 \\
\hline \multirow[t]{2}{*}{ D Unspecified behavior } & 40 & $5 \%$ & BRL $6,050.26$ & $3 \%$ & BRL 151.26 \\
\hline & 860 & $100 \%$ & BRL $241,103.72$ & $100 \%$ & BRL 280.35 \\
\hline
\end{tabular}

The result of this research has shown that consultations and supplementary examinations are the main cardiovascular care services accessed by users that are cancer survivors, totaling $88 \%$ of the accounts analyzed. This confirms the hypothesis that these users frequently start using care in other specialties, such as cardiology, in the case of our study.

Performing cardiovascular examinations in the routine monitoring of patients treated for cancer is a conduct supported by the national and international literature, bringing benefits for early diagnosis of cardiovascular events in cancer survivors. ${ }^{7,28}$ The main objective of conducting periodic consultations for cardiovascular monitoring is early diagnosis (through medical history, physical examination, and supplementary examinations), as well as providing educational guidance for cancer survivors in order to reduce the risk of developing heart diseases; this includes lifestyle advice, avoiding addictions such as cigarettes and alcohol, and encouraging weight loss and regular physical activity. ${ }^{7,28}$ This guidance has a positive effect not only on cardiovascular risk factors but also on the quality of life of cancer survivors.

We noted that $74 \%$ of the supplementary examinations requested were aimed at screening of cardiovascular diseases (ultrasound, stress test, and electrocardiogram). These supplementary examinations are easy to perform, have a lower cost, and are considered effective for monitoring cardiovascular events. ${ }^{1,729}$ The prevention of cardiovascular events has already been defined in the literature as being effective and economically viable, as it reduces the costs of acute events such as heart attacks, cerebrovascular accidents, heart failure or arrhythmias. ${ }^{30}$ This set of measures aims to reduce the risk of morbidity and mortality and improve the quality of life of cancer 
patients, without interfering with the specific cancer treatment, where possible. ${ }^{7}$

In this sample, it has been shown that only $2 \%$ of the charges were related to hospitalization and accounted for $51 \%$ of the total cost of the sample analyzed. It is assumed that the monitoring of cancer survivors is a fundamentally important strategy to reduce costs for the health system and improving the user's life. In this case, the implementation of management programs for chronic cases and/or management of patients by diseases or specialties is recommended, focused on prevention and education for self-care. ${ }^{31-33}$ As such, cancer survivors need overall monitoring of their health by a multidisciplinary team, and not only by their oncologist.

The prevalence of three types of cancer was noted in this study, including breast (37\%), prostate (15\%), and colon $(9 \%)$ cancer, consistent with the epidemiological profile found in the Brazilian population. ${ }^{2}$ There was a predominance of breast in relation to prostate neoplasms, because most of the accounts belonged to female users (73\%). The distribution of cardiovascular care costs according to the type of neoplasm was very similar. The highest frequency of use was related to consultations and supplementary examinations and the highest cost was that of hospitalizations (ranging from 52 to $69 \%$ of the total cost), regardless of the type of cancer. When analyzing the average cost per account among the three most common neoplasms, we found that cardiovascular care spending was higher in prostate cancer (BRL 435,42) compared to colon and breast cancer (BRL 336.90 and BRL 308.42, respectively). This result is justified if we consider that the average age of users who survived prostate cancer (70.49) was higher than that of the other neoplasms (66.16 and 62.10, respectively). There was, therefore, a greater need for use of cardiology care. ${ }^{31-33} \mathrm{~A}$ higher average cost per account was expected in breast neoplasms, considering that these users normally undergo treatment using radiotherapy and chemotherapy with known cardiotoxicity, such as doxorubicin and traztuzumab. ${ }^{7,28}$ However, the average cost per account in breast neoplasms was lower than that of prostate and colon cancer. We assumed the factors of age and user monitoring time may have influenced this result. Another reason is that complications of cardiovascular origin related specifically to the cancer treatment do not require high-cost interventions. For example, echocardiography is a simple, low-cost examination and, in most cases, sufficient for the detection of cardiotoxicity related to chemotherapy, without the need for additional examinations or high-cost procedures. ${ }^{7,28}$
One of the limitations of our study is that the selection of the accounts was performed based on the ICD provided by the attending physician, which may result in mismatches in the classification. Increased monitoring time and a greater number of cancer survivor accounts is recommended for a more detailed analysis of the costs in the use of cardiology care, especially in high-cost procedures. An analysis of cardiovascular care according to the type of treatment (chemotherapy and radiotherapy protocols, for example) is also deemed necessary. We were not able to identify users with preexisting cardiovascular disease upon diagnosis of cancer, which may result in a sample selection bias. Time between the use of cardiology care and the end of cancer treatment could not be identified, either. Finally, the need for a control group was identified in order to be able to compare and quantify the use of cardiology care in the cancer survivor group, which will be conducted in the future by our research team.

\section{Conclusion}

Analysis of the medical and hospital accounts of the users of a health insurance provider previously submitted to any cancer treatment enabled us to identify that this group of patients also uses health care in the cardiology area. The main health care services used are consultations and supplementary examinations aimed at the prevention of cardiovascular diseases. Hospital admissions for complications of cardiovascular origin, although uncommon, represent an important care cost for the health insurance provider. Therefore, it is essential for the management of chronic cases to include patients who have undergone some form of cancer treatment, encouraging self-care and the prevention of cardiovascular diseases in order to reduce costs for the health insurance provider and improve the quality of health care.

\section{Resumo}

Análise dos custos e da qualidade da assistência cardiovascular no seguimento oncológico

Objetivo: analisar os custos assistenciais com afecções cardiovasculares utilizados por usuários sobreviventes do câncer de uma operadora de saúde suplementar na região Sul do Brasil.

Método: foi desenvolvido um estudo observacional, transversal, retrospectivo, com estratégia quali-quantitativa, através de atividade de auditoria interna analítica de contas médico-hospitalares.

Resultados: foram analisadas 860 contas, de 2012 a 2015, com $73 \%$ de usuários femininos e uma média etária de 
62,38 anos, somando um custo total direto de R $\$ 241.103,72$. Houve predomínio de $37 \%$ de neoplasias de mamas, $15 \%$ de próstata e $9 \%$ de cólon. Com relação à assistência cardiovascular, $44 \%$ foram consultas, $44 \%$ foram exames complementares, $10 \%$ foram atendimentos de emergência e $3 \%$ foram hospitalizações. Os custos em assistência cardiovascular foram maiores nas hospitalizações (51\%), seguidos pelos exames complementares (37\%), pelas consultas (8\%) e pelos atendimentos emergenciais (4\%).

Conclusão: os sobreviventes de câncer habitualmente utilizam a assistência à saúde em outras especialidades, como a cardiologia, e o principal custo é em hospitalização. Recomenda-se investir em prevenção (consultas e exames), assim como em programas de gestão de casos crônicos para reduzir os custos e melhorar a qualidade da assistência à saúde.

Palavras-chave: saúde suplementar, custo e análise de custo, serviços de cardiologia, oncologia, prevenção de doenças.

\section{References}

1. Albini A, Pennesi G, Donatelli F, Cammarota R, De Flora S, Noonan DM. Cardiotoxicity of anticancer drugs: the need for cardio-oncology and cardiooncological prevention. J Natl Cancer Inst. 2009; 102(1):14-25.

2. Facina T. Estimativa 2014 - Incidência de Câncer no Brasil. Rev Bras Cancerol. 2014. 60(1):63. Available from: http://www.inca.gov.br/rbc/n_60/v01/pdf/11resenha-estimativa-2014-incidencia-de-cancer-no-brasil.pdf

3. Sereno M, Brunello A, Chiappori A, Barriuso J, Casado E, Belda C, et al. Cardiac toxicity: old and new issues in anti-cancer drugs. Clin Transl Oncol. 2008; 10(1):35-46

4. Yeh ET, Bickford CL. Cardiovascular complications of cancer therapy: incidence, pathogenesis, diagnosis, and management. J Am Coll Cardiol. 2009; 53(24):2231-47

5. Ferlay J, Soerjomataram I, Ervik M, Dikshit R, Eser S, Mathers C, et al. GLOBOCAN 2012 v1.0, Cancer Incidence and Mortality Worldwide: IARC CancerBase No. 11. Lyon: International Agency for Research on Cancer; 2013 [cited 2015 Sep 3]. Available from: http://globocan.iarc.fr.

6. Siegel R, Ma J, Zou Z, Jemal A. Cancer statistics, 2014. CA Cancer J Clin. 2014; 64(1):9-29.

7. Kalil Filho R, Hajjar LA, Bacal F, Hoff PM, Diz M Del P, Galas FRBG, et al. I Diretriz Brasileira de Cardio-Oncologia da Sociedade Brasileira de Cardiologia. Arq Bras Cardiol. 2011; 96(2 Supl. 1):1-52.

8. Ewer MS, Ewer SM. Cardiotoxicity of anticancer treatments: what the cardiologist need to know. Nature Rev Cardiol. 2010; 7(10):564-75.

9. Wu AH. Cardiotoxic drugs: clinical monitoring and decision making. Heart. 2008; 94(11):1503-9.

10. Monsuez JJ, Charniot JC, Vignat N, Artigou JY. Cardiac side-effects of cancer chemotherapy. Int J Cardiol. 2010; 144(1):3-15.

11. Santos MVC, Paiva MG, Macedo CRDP, Petrilli AS, Azeka E, Jatene IB, et al. I Diretriz Brasileira de Cardio-Oncologia Pediátrica da Sociedade Brasileira de Cardiologia. Arq Bras Cardiol. 2013; 100(5 Supl. 1):1-68.

12. Anderson JL, Adams CD, Antman EM, Bridges CR, Califf RM, Casey DE Jr, et al. ACC/AHA 2007 guidelines for the management of patients with unstable angina/non ST-elevation myocardial infarction: a report of the American heart Association Task Force on Practice Guidelines. Circulation. 2007; 116(7):e148-304.

13. Kushner FG, Hand M, Smith SC Jr, King SB 3rd, Anderson JL, Antman EM, et al. 2009 focused updates: ACC/AHA guidelines for the management of patients with ST-elevation myocardial infarction (updating the 2004 guideline and 2007 focused update) and ACC/AHA/SCAI guidelines on percutaneous coronary intervention (updating the 2005 guideline and 2007 focused update) a report of the American College of Cardiology Foundation American Heart Association Task Force on Practice Guidelines. J Am Coll Cardiol. 2009; 54(23):2205-41.

14. Sarkiss MG, Yusuf SW, Warneke CL, Botz G, Lakkis N, Hirch-Ginsburg C, et al. Impact of aspirin therapy in cancer patients with thrombocytopenia and acute coronary syndromes. Cancer. 2007; 109(3):621-7.

15. Krone RJ. Managing coronary artery disease in the cancer patient. Prog Cardiovasc Dis. 2010; 53(2):149-56

16. Cardiac Society of Australia and New Zealand. Guidelines for the management of antiplatelet therapy in patients with coronary stents undergoingnoncardiac surgery. Heart Lung Circ. 2010; 19(1):2-10.

17. Lyman GH, Khorana AA, Falanga A, Clarke-Pearson D, Flowers C, Jahanzeb M, et al.; American Society of Clinical Oncology. American Society of Clinical Oncology guideline: recommendations for venous thromboembolism prophylaxis and treatment in patients with cancer. J Clin Oncol. 2007; 25(34):5490-505.

18. Guglin M, Aljayeh M, Saiyad S, Ali R, Curtis AB. Introducing a new entity: chemotherapy-induced arrhythmia. Europace. 2009; 11(12):1579-86

19. Onaitis M, D'Amico T, Zhao Y, O'Brien S, Harpole D. Risk factors for atrial fibrillation after lung cancer surgery: analysis of the Society of Thoracic Surgeons general thoracic surgery database. Ann Thorac Surg. 2010; 90(2):368-74.

20. Azeka E, Jatene MB, Jatene IB, Horowitz ESK, Branco KC, Souza Neto JD, et al. I Diretriz Brasileira de Insuficiência Cardíaca e Transplante Cardíaco, no feto, na criança e em adultos com cardiopatia congênita, da Sociedade Brasileira de Cardiologia. Arq Bras Cardiol. 2014; 103(6 Supl. 2):1-126.

21. Lipshulz SE, Adams MJ, Colan SD, Constine LS, Herman EH, Hsu DT, et al.; American Heart Association Congenital Heart Defects Committee of the Council on Cardiovascular Disease in the Young, Council on Basic Cardiovascular Science, Council on Cardiovascular and Stroke Nursing, Council on Cardiovascular Radiology. Long-term cardiovascular toxicity in children, adolescents, and young adults who receive cancer therapy: pathophysiology, course, monitoring, management, prevention, and research directions: a scientific statement from the American Heart Association. Circulation. 2013; 128(17):1927-95. Erratum in: Circulation. 2013; 128(19):e394.

22. Cardinale D, Sandri MT, Martinoni A, Tricca A, Civelli M, Lamantia G, et al. Left ventricular dysfunction predicted by early troponin I release after high-dose chemotherapy. J Am Coll Cardiol. 2000; 36(2)517-22.

23. Cardinale D, Sandri MT, Martinoni A, Borghini E, Civelli M, Lamantia G, et al. Myocardial injury revealed by plasma troponin I in breast cancer treated with high-dose chemotherapy. Ann Oncol. 2002; 13(5):710-5.

24. Shwartz RG, McKenzie WB, Alexander J, Sager P, D'Souza A, Manatunga A, et al. Congestive heart failure and left ventricular dysfunction complicating doxorubicin therapy. Seven-year experience using serial radionuclide angiocardiography. Am J Med. 1987; 82(6):1109-18.

25. Brasil. Ministério da Saúde. Agência Nacional de Saúde Suplementar. O impacto da regulamentação no setor de saúde suplementar. Rio de Janeiro: ANS; 2001.

26. Brasil. Ministério da Saúde. Informações de Saúde. Classificação Estatística Internacional de Doenças e Problemas Relacionados à Saúde. Décima Revisão (CID10). Versão 2008. [cited 2015 Mar 20]. Available from: http://www. datasus.gov.br/cid10/V2008/WebHelp/cid10.htm.

27. Thom TJ, Epstein FH. Heart disease, cancer, and stroke mortality trends and their interrelations: an international perspective. Circulation. 1994; 90(1):574-82.

28. Montazeri K, Unitt C, Foody JM, Harris JR, Partridge AH, Moslehi J. ABCDE steps to prevent heart disease in breast cancer survivors. Circulation. 2014; 130(18):e157-9.

29. Altena R, Perik PJ, van Veldhuisen DJ, de Vries EG, Gietema JA. Cardiovascular toxicity caused by cancer treatment: strategies for early detection. Lancet Oncol. 2009; 10(4):391-9.

30. Simão AF, Precoma DB, Andrade JP, Correa Filho H, Saraiva JFK, Oliveira GMM, et al. I Diretriz Brasileira de Prevenção Cardiovascular. Arq Bras Cardiol. 2013; 101(6 Supl. 2):1-63

31. World Health Organization (WHO). Innovative Care for Chronic Conditions - Building Bloks for Action. Global Report. Noncommunicable Disease and Mental Health. Geneva: World Health Organization; 2002.

32. Organização Mundial da Saúde (OMS). Cuidados inovadores para condições crônicas: componentes estruturais de ação. Relatório mundial. Brasília: Organização Mundial da Saúde; 2003.

33. Brasil. Ministério da Saúde. Agência Nacional de Saúde Suplementar (ANS) Programas de promoção da saúde e prevenção de riscos e doenças. [cited 2015 Apr 31]. Available from: https://www.ans.gov.br/images/stories/ Materiais_para_pesquisa/Materiais_por_assunto/ProdEditorialANS_Manual_ Tecnico_de_Promocao_da_saude_no_setor_de_SS.pdf. 